\title{
A Study on the Teaching Content of Martial Arts in Primary and Secondary Schools from the Perspective of Cultural Inheritance
}

\author{
Caixia Wang, Jun Liu \\ School of Sport Science, Nantong University, Nantong, China \\ Email:1119809975@qq.com
}

How to cite this paper: Wang, C. X., \& Liu, J. (2018). A Study on the Teaching Content of Martial Arts in Primary and Secondary Schools from the Perspective of Cultural Inheritance. Advances in Physical Education, 8, 1-6.

https://doi.org/10.4236/ape.2018.81001

Received: November 14, 2017

Accepted: December 12, 2017

Published: December 15, 2017

Copyright (c) 2018 by authors and Scientific Research Publishing Inc. This work is licensed under the Creative Commons Attribution International License (CC BY 4.0).

http://creativecommons.org/licenses/by/4.0/

\begin{abstract}
In the process of martial artistic teaching, the education and inheritance of culture are the relatively weak in the teaching of martial arts. The traditional sport of the Chinese nation-martial arts, as an important part of the traditional culture of the Chinese nation, has important significance and value. It can not be ignored during the primary and secondary school teaching process. School martial artistic teaching not only teaches us skills, but also has the cultural content, so as to truly carry forward arts culture (The Publicity Department of the Communist Party of China Central Committee, 2006). This paper uses the method of literature and logical analysis to analyze and learn the content of martial artistic teaching in primary and secondary schools, comprehensively understand the role of martial arts in the teaching process of primary and middle schools, re-integrate the contents and cultural connotations of traditional martial arts, to be a kind of education connected with teaching content.
\end{abstract}

\section{Keywords}

Cultural Inheritance, Martial Arts, Teaching Content

\section{Introduction}

Culture is an important form in national soft power, which is an indispensable part of the implementation of national strategy. Since the 18th CPC National Congress, the General Secretary of the Communist Party of China has published many important articles on inheriting and carried forward the fine culture of the Chinese nation and realized the great rejuvenation of the Chinese nation. Firstly a country's strong situation is profound culture. History shows that the continu- 
ation of national culture is the core of national vitality, creativity and cohesion. The Chinese nation is a country with five thousand years of splendid culture. It is Cultural inheritance that is an important mission to realize the great rejuvenation of the Chinese nation, highlight the unique cultural charm of the Chinese nation and enhance the image of the great powers of the Chinese nation. The main content of martial arts is the art of attack and defence, and the movement form is a series of skills and trick as well as wrestling, focusing on internal and external Chinese traditional sports.

Martial arts are the accumulation during thousands of years of culture of the Chinese nation, and it is a kind of physical culture and martial artistic culture. Martial arts with its own unique charm of the cultural form of the Chinese nation gave birth to the noble children of Chinese morality, shaping the glory image of the Chinese nation. The school is the cradle on educating people, meanwhile it is the base of cultural heritage. Primary and secondary school period is a good time to develop a person's personality (Guo \& Wang, 2011). Communication of martial artistic culture in primary and secondary school has important impact on the development of students' personality, while martial arts heritage benefits the construction of the spiritual home of the Chinese nation and the realization of the great rejuvenation of the Chinese nation. At present, martial arts teaching only emphasizes the inheritance of technology, ignoring the cultural heritage in primary and middle schools.

\section{School Is an Important Place for Martial Artistic Culture}

School is the main place of cultural transmission, since ancient times, there is a closed contact between martial arts and school education. School education is an important method of martial arts culture inheritance, and martial artistic education is the core carrier of martial artistic development thousands of years.

China's earliest martial artistic education is from the Shang and Zhou Dynasties, martial education during this period had an important content-shooting which is belonging to martial arts. In the Zhou Dynasty, the development of the "six arts" included "ceremony, shooting, Defense, music, number and book". Specifically, "ceremony" contained a variety of martial artistic etiquette culture, "shot and defense" were for military training Special talent. Martial artistic teaching is a specialized course, and the relationship between "music" teaching dancing and martial arts is contacted. Dance practice can be regarded as our current martial artistic routine exercise.

In the Revolution of 1911, Sun Yat-sen advocated the idea of "strong country with strong martial arts" the nationalist ideology, more and more people began to pay attention on martial arts. Martial arts are physical education teaching content in many schools. The Well-known sports educator Xu Yibing recommended to the Ministry of Education to publish "rectify the national school sports on the Ministry of Education" in 1914 and recommended martial arts officially classified as a formal course of sports in high school, junior high school 
and normal school. In 1915, the National Education Association of the Beijing Sports Research Institute proposed a proposal according with Xu Yibing. In the same year, when Cai Yuanpei as chief of education and some important officials are openly admitted to the school sports martial arts project, which is the beginning of martial arts about school sports. With the sustainably development of the school sports content, Martial arts has a closed relationship with supports of many people of insight on modern society: in the political community, Mr. Sun Yat-sen advocated "strong country with strong martial arts" nationalist ideology; in the education sector, Mr. Tao Xingzhi advocated "the martial arts to develop healthy physique and spirit" of the sports ideas; In the sports sector, Cai Yuanpei advocated "China's education should pay attention to martial arts, which not only to defend the country, but also physical fitness" and other ideas (Ren, 2003). All sectors of the martial articulated education advocated ideas reflecting the value and significance of martial artistically as a school teaching content, but also the school martial arts including school teaching content experience nearly a hundred years of status is still a solid historical origin.

Martial arts formally are incorporated into the primary and secondary school physical education syllabus in 1961, after that, the martial arts teaching content of the many amendments also shows that martial arts as an educational content is inherited and developed, modern martial arts developing in the direction of the development of standardization and entered a new period of vigorous development.

\section{The Shortcomings of Current Martial Artistic Teaching in Primary and Secondary Schools}

Martial arts is of great significance to the improvement of national constitution, the inheritance of culture and the promotion of national spirit, but the development of school martial arts at this stage is not satisfactory (Qiu, 2007). Although the martial arts is a compulsory content, in the context of the examinationoriented education is still undoubtedly. The teaching content is single and just stay in state of the basic movements of martial arts, simple routine teaching level still cannot escape "primary school five steps of boxing, high school five steps of boxing" teaching content. Teaching materials is the carrier of teaching content, but the martial arts teaching materials are mostly martial arts action to explain, but the martial arts action implied talk about too little. Teacher's level for the martial artistic culture is not high so that the focus of martial artistic teaching is still martial arts action to explain. The students in the process of practicing martial arts cannot understand the martial arts culture, not to expect the imagination of martial arts, thus they gradually lost interest in martial arts class. Martial arts focus on the traditional Chinese culture display, martial arts contain the ritual culture, respect for teachers and martial arts, self-improvement, respect for the strong unity of patriotic spirit, it is the "external-internal harmony" philosophy of culture. School martial arts teaching is lack of traditional culture of infiltration, 
for the martial arts culture itself, the cultivation of student values and the development of the country.

\section{Inheritance of Martial Arts Culture in the Process of in Primary and Secondary Education}

According to the characteristics of "hidden" and "explicit" in the curriculum theory, the courses are divided into "hidden courses" and "explicit courses". Combined with the classification of curriculum thinking, martial arts culture in the teaching activities of the content can be divided into: visible martial arts culture and invisible martial arts culture. The visible culture of martial arts is the culture that is seen in martial arts teaching, which exists in various forms. The invisible martial arts culture is the spiritual value of martial arts, spirit, meaning and origin in the traditional culture of the Chinese nation Elements.

Martial arts' visible culture is more intuitive to show, including the basic martial arts exercises, routine training, martial arts etiquette culture learning, martial arts theory books learning, also including the boxing, genre and so on. Martial arts' visual culture education is the most martial arts in the dissemination of the most important forms of expression, learning the martial arts visual culture, can achieve physical fitness, self-defense.

Martial arts' invisible culture is the martial arts based on its form contains the Chinese nation's outstanding ideology and culture, also is the core culture of martial arts and spiritual culture, including "external-internal harmony" thinking, "unity of knowledge and behavior" thinking, traditional spirit of martial arts (respect for the strong, fair competition and other ideas), the Chinese national spirit (patriotism, peace, self-improvement, etc.) and so on. It is precise because of the connotation of martial arts culture which decides to continue to flourish the development of martial arts, the formation of many boxing, many schools of profound cultural phenomenon, these ideas and culture are the reflection of thousands of years of traditional Chinese culture and the precious spirit of the Chinese nation wealth.

\section{In Heritance of Chinese Culture in Martial Arts Teaching in Primary and Middle Schools}

The inheritance of culture is long-term process of slowly internalization. It is divided into the generation of action skills and spiritual connotation of the sublimation process.

Martial artistic teaching in primary and secondary schools should cultivate students' ritual culture in the teaching of martial arts technical action (Liu, 2011). Etiquette was an original ritual; the existence of the ritual is very necessary. For example, flag-raising ceremony can inspire our patriotism, join the party swearing ceremony can make us love the party organization, loyal to the party organization, each class will have teachers and students greet ritual, which is the performance of mutual respect between teachers and students, and so on. 
During the martial arts teaching process, there are hold fist salute, bow ceremony, holding knife ceremony, holding sword ceremony, holding guns and so on. Martial arts etiquette is a very good moral education content, etiquette teach in the teaching process is strictly enforced, is conducive to the development of student behavior habits.

Martial arts education in teaching process is in primary and middle schools. This is closely related to the origin of martial arts, martial arts originated in the struggle: the struggle between man and the beast, the struggle of people, it has "Pandora magic", martial arts with double-sided nature which requires martial arts must have martial spirit, no martial spirit, martial arts may be just a homicide weapon. Martial spirit belongs to the category of social consciousness and has an educational effect on people. The infiltration of martial arts in the teaching of primary and secondary schools is conducive to the transmission of traditional Chinese virtues, such as courageous, maintaining social fairness. Be dare to fight against social behavior, respect for teachers and develop the habit of good character.

Primary and secondary school martial arts practice are based on the profound understanding of the cultural essence of martial arts. When training students on shadowboxing, we should guide the students to experience the ideology of "external-internal harmony". Through practicing the basic skills of martial arts, we can understand the culture in the way of winning. Through studying the method of breath, the "air theory" and "doctrine theory" of Laozi in martial arts can be realized. By studying the "five birds" and other fitness skills and feel the martial arts, we can experience the philosophical ideas well.

\section{Conclusion}

Martial arts are the carrier of Chinese traditional culture. The primary and middle schools should take the responsibility for inheriting the Chinese culture. The rich content of martial arts teaching is of great significance to the inheritance of martial arts culture. The inheritance of martial arts culture is a process of gradual internalization, which is a process of sublimation from technical action to spiritual connotation. In the course of martial arts teaching, we should pay more attention to the cultivation of martial arts consciousness and fundamentally change the thought of "focus on technology and make light of theory", so that martial arts culture can be inherited well.

Suggestions about promoting school martial arts teaching: 1) It should change the concept of martial arts education, and emphasize on martial arts culture and education. 2) It should adjust the teaching content of martial arts, and pay more attention to high reputation with fantastic skills. 3) It should improve teachers' martial arts teaching ability. 4) It should build a good school atmosphere to carry the torch for martial arts culture.

\section{References}

Guo, J. P., \& Wang, Y. G. (2011). On the Cause of Traditional Chinese Wushu Culture. 
Literary Exposition: Theory.

Liu, C. P. (2011). Contemporary School Martial Arts Education Value. Journal of Beijing Sport University, 2011, 2.

Qiu, P. X. (2007). Chinese Martial Arts Culture. Shanghai: Shanghai People's Publishing House.

Ren, H. (2003). Foreign Mass Sports. Beijing: Beijing Sports University Press.

The Publicity Department of the Communist Party of China Central Committee. (2006). General Secretary Xi Jinping Series of Important Readings. Beijing: People's Publishing House. 